This is a self-archived version of the original publication.

\author{
Reference: \\ Renfors, S. Internationalising Higher Tourism Education: \\ The Case of Curriculum Design in the Central Baltic Area \\ Journal of Teaching in Travel \& Tourism, 18:4 (2018), \\ 315-331, DOI: 10.1080/15313220.2018.1491816
}




\title{
Internationalising Higher Tourism Education: The Case of Curriculum Design in the Central Baltic Area
}

\begin{abstract}
The aim of this article is to increase understanding of the process of curriculum design when incorporating an international dimension into a curriculum in higher tourism education. The process of the internationalisation of the curriculum design is investigated against a theoretical basis and described from a practical perspective by presenting a case from the Central Baltic Area. In this case, the purpose of the internationalisation of the curriculum is to provide an aligned skillset and knowledge necessary to support the development of the Central Baltic Area as a common tourism destination. First, a relevant and mutual skillset was identified by reviewing the existing curricula $(\mathrm{N}=17)$ and national tourism strategies and plans $(\mathrm{N}=3)$ as well as by interviewing representatives of tourism organisations $(\mathrm{N}=103)$. Then, the identified skills and knowledge were translated into a joint curriculum and teaching processes.
\end{abstract}

Keywords: internationalisation; curriculum design; tourism education; the Baltic Sea

\section{Introduction}

This article focuses on the internationalisation of the curriculum in higher tourism education, especially on curriculum design. Higher education is globally subject to profound changes due to its cross-border delivery, increasing competition and commercialisation (deWit, 2010; Dobbins, Knill, \& Vögtle, 2011). As a result, the nature of cooperation between the higher education institutions in Europe is changing and the emphasis is being shifted from physical mobility to the internationalisation of the curricula and teaching and learning processes.

However, the internationalisation of the curriculum is often one of the underdeveloped aspects in the European higher education systems (Laitinen, 2015). deWit and Hunter (2015) 
reminded that while greater attention is being paid to incorporating an international dimension into the curriculum, the operationalisation of the curriculum within the institutions still constitutes a true challenge. It is not always evident what the internationalisation of the curriculum means in practice in higher education institutions. There may be no clear vision or understanding of what the desired outcome should be like and, given the absence of a widely accepted model, how this outcome can be achieved in practice (Dunne, 2011). In fact, the internationalisation of the curriculum often seems to take place at a rhetorical level than in reality (Reid \& Spencer-Oatey, 2013). Svensson and Wihlborg (2010) claimed that the internationalisation of higher education often seems to be to a great extent accidental, rather than clearly intended.

Werner (2008) and Zehner and Lichtmannegger (2008) stressed that the internationalisation of the curriculum is particularly important in tourism education. According to Werner (2008), tourism itself is by definition a highly international activity and both tourism enterprises and tourism employees are strongly affiliated to internationalisation due to the very nature of the business. Ayoun et al. (2010) argued that remarkable growth in international business has created a need for internationally competent and qualified personnel who are able to work effectively in a multicultural and global society. Because the tourism industry is highly diverse and internationally oriented, the employers rely on their workforce to be involved with international tourists and to greet and meet their needs (Hearns, Devine, \& Baum, 2007; Sangpikul, 2009). They work in a multicultural business environment and are constantly in contact with various nationalities as customers.

The internationalisation of the curriculum and its operationalisation can be interpreted in many ways in higher education institutions offering tourism degrees. Previous studies include institutional and programme level examples of the internationalisation of the curriculum in tourism and hospitality education. Several researchers (Black, 2004; Brookes \& Becket, 2011; 
Sangpikul, 2009; Zhang et al., 2009;) have highlighted the different factors affecting the internationalisation of the curricula such as faculty members, students, international exchanges, curriculum content and delivery, as well as international alliances and partnerships. The authors also examined certain elements of the internationalisation of the curricula such as study tours abroad (Williams \& Best, 2014) and international collaborative learning projects (Deale, 2015). Furthermore, the studies have focused on strategies and policies of internationalisation in higher education institutions providing tourism education (Jordan, 2008; Zehner \& Lichtmannegger, 2008). In conclusion, the studies have concentrated on the internationalisation of the curricula mostly at institutional level. They have explored the factors, strategies and policies of internationalisation in tourism and hospitality education programmes and identified the extent to which these programmes are internationalised to produce graduates capable of working within the global tourism industry.

Brookes and Becket (2011) concluded that while efforts are made to promote international dimensions within individual tourism programmes, in programme documentation and on websites, it is not yet clear how the programmes are internationalised. In other words, there are hardly any studies on the internationalisation of the curriculum in higher tourism education which focus on its design. In addition, studies on the internationalisation of the curriculum in higher tourism education have mostly concentrated on a single institution (Black, 2004; Zehner \& Lichtmannegger, 2008) or a single country such as Thailand, China, or the UK (Brookes \& Becket, 2011; Sangpikul, 2009; Zhang et al., 2009). There is lack of studies on the internationalisation of the curriculum in higher tourism education with the focus on examining how to design a joint curriculum for several countries and how the internationalisation of the curriculum design can be achieved in practice.

The aim of this article is to increase understanding of the process of curriculum design when incorporating an international dimension into a curriculum in higher tourism education. 
First, the main areas in the internationalisation of the curriculum design are investigated against a theoretical basis. Secondly, the process of the internationalisation of the curriculum design is described from a practical perspective. The article presents a case of designing a joint curriculum in cooperation by four universities situated in three European countries: Finland, Estonia, and Latvia. The purpose of the curriculum is to provide an aligned skillset and knowledge necessary for meeting the new challenges in the industry and for taking advantage of the possibilities the tourism industry provides, in particular, because international tourism and international tourism education are expected to increase their importance in these countries. Due to the vocational nature of the curriculum, education and the tourism industry are closely connected. Therefore, the needs and expectations of the tourism industry have a priority in this curriculum design process.

The economic rationales including growth, competitiveness and labour market requirements were the primary reasons for the internationalisation of the curriculum in this case. According to the European Union Strategy for the Baltic Sea Region (EUSBSR), the Central Baltic Area, i.e. Finland, Estonia, and Latvia should be developed as a common tourism destination in order to receive more international tourists, especially from the other continents. In fact, the number of foreign overnight stays is increasing in all three countries (Ministry of Economics of the Republic of Latvia, 2017; Visit Estonia, 2017; Visit Finland, 2017), and the countries share common challenges and possibilities in tourism business development. One of the common challenges includes improving education and skills in tourism to respond to the growth of tourism. In particular, the small and medium-sized enterprises (SMEs) experience a shortage of skilled workforce because education does not fulfil the needs of the labour market. It is imperative to identify and align the needed skills and translate them into curricula to be able to develop the area as a coherent tourism destination and to provide education and training where these skills are learnt. 
Furthermore, academic rationales with the development of the international dimension in teaching, profile and status, as well as the improvement of the quality were considered important. The internationalisation of the curriculum enhances the international competiveness and attractiveness of higher tourism education in the Central Baltic Area. The educational demand is growing, as the number of degree-seeking international students has clearly increased during the 2000's and full degree programmes in English have been established (Garam, 2016; Laitinen, 2015). However, there is a need to further internationalise and strengthen the educational system in order to remain a globally competitive area (Central Baltic Programme 2014-2020).

In this case, the internationalisation of the curriculum also contributes to the goal of the European Union (EU) to pay more attention to the development of international curricula and learning outcomes as Europeanisation enables cooperation between higher education institutions in a broader geographical context. The phenomena of Europeanisation initially began in the 1990's as part of the move to economic and political integration with horizontal mobility and cooperation (ERASMUS) and subsequently the standardization of study programmes and degrees known as the Bologna Process (Altbach \& Knight, 2007; deWit, Deca, \& Hunter, 2015; Teichler, 2004). Since its beginning, the Bologna Process was intended to strengthen the competitiveness and attractiveness of European higher education by creating a framework for an international dimension in higher education (deWit et al., 2015).

The article is organised as follows. The literature review describes the definition of the internationalisation of the curriculum and how the international dimension is included in the curriculum design in higher tourism education. Next, the article presents a case of the internationalisation of the curriculum design in the Central Baltic Area. The process of curriculum design is explored with attention on the details concerning this particular case. Finally, the discussion focuses on the advantages and disadvantages of the design process. 


\section{Definition of the Internationalisation of the Curriculum}

The term international emphasises the notion of nation and refers to the relationship between and among different nations and countries (Knight, 2004). It addresses an increase in bordercrossing activities (Teicler, 2004). Internationalisation includes the policies and practices undertaken by academic systems and institutions, and even individuals, to cope with the global academic environment (Altbach \& Knight, 2007). The most frequently cited and the most widely accepted definition of the internationalisation of higher education is that by Knight (2004, p.11): "internationalisation at the institutional level is the process of integrating an international, intercultural, or global dimension into the purpose, functions, or delivery of postsecondary education."

According to Knight and deWit (1995), an internationalised curriculum has an international orientation in content. It aims at preparing students for performing professionally and socially in an international and multicultural context, and it is designed for domestic students and/or foreign students. According to Leask (2009), the internationalisation of the curriculum refers to the incorporation of an international and intercultural dimension into the content as well as to the teaching and learning arrangements of the curriculum. This definition implies change since learning outcomes, content, teaching and learning activities and assessment tasks are internationalised through a planned and systematic process to ensure that all students develop international, intercultural and global perspectives (deWit \& Hunter, 2015). In addition, Tagaki (2015) considered the internationalisation of the curriculum as a way of internationalising programmes as products composed of international contents and designed for targeted students or defined professions with the aim of generating income and enhancing the international competitiveness of graduates and institutions in global economy. 
This article concentrates on formal curriculum development. Leask (2015) defines a formal curriculum as a syllabus and planned schedule of experiences and activities the student must undertake as part of the programme. According to Leask (2009), a formal curriculum is a sequenced programme of teaching and learning activities and experiences organised around defined content areas, topics, and resources. The objectives of a formal curriculum are assessed in various ways including examinations, various types of assignments and practical activities. In higher tourism education, a curriculum is defined as a series of courses of instruction that lead to graduation, a degree or a similar terminal award and as a complete educational experience packaged as a degree programme (Gunn, 1998; Tribe, 2002).

In this article, the internationalisation of the curriculum is defined as the incorporation of an international dimension into the content, teaching, and learning arrangements of the curriculum to ensure that the students develop international perspectives that support the growth and competiveness of the Central Baltic Area as a common tourism destination. In this case, the curriculum is a series of courses packed into a specialisation module of tourism business development including eight courses with 33 European Credit Transfer and Accumulation System (ECTS) credits, which will be integrated as a part of the tourism bachelor degree programmes of the universities involved. The curriculum consists of a sequenced programme of teaching and learning activities and experiences organised around the topic of tourism business development in the context of the Central Baltic Area. The students are also provided an official certificate after the completion of each study course and a separate diploma after completing the whole module.

\section{Including an International Dimension into a Curriculum in Higher Tourism Education}

There are several aspects of importance to be considered, when planning the internationalisation of the curriculum design (Table 1). First, it is necessary to determine the rationales for 
internationalisation and the purpose for internationalising the curriculum (Korhonen \& Weil, 2015; Leask, 2005). Luxon and Peelo (2009) noted that the rationales for internationalisation vary considerably between higher education institutions, and there exists a range of possible curriculum design and course development responses to internationalisation. As deWit (2010) stated, when we talk about internationalisation, it is important to distinguish the question of why we are internationalising higher education from what we mean by internationalisation.

Secondly, the key aspects include course outcomes, content, assessment, learning environment, and resources. Alignment of these different elements assists the integration of internationalisation across the programme. In addition, attention to one of the elements often requires adjustment in another element. (Leask, 2005, p. 123.) As Webb (2005) emphasised, the internationalisation of the curriculum must involve both elements: "what is taught" and "how it is taught".

Table 1. The main aspects of the internationalisation of the curriculum design modified on the basis of Brookes and Becket (2011), deWit (2010) and Leask (2005).

Table 1 near here

When the content of the curriculum is internationalised, the students gain understanding and a global perspective of the discipline (Ryan, 2005). This means that lecturers have to be able to locate and incorporate a range of culturally appropriate material into their teaching. According to Leask (2005, p. 124), the course content can be internationalised by including case studies and examples from different countries, specific reference to intercultural issues in professional practice, comparative contemporary international and local content, investigation of professional practices in other cultures or by exploring how knowledge may be constructed differently in the discipline from culture to culture. 
According to Leask (2009), activity design is especially critical. Ideally, students are required to work on activities that are completed with a meaningful exchange of cultural information (Leask, 2009). Black (2004) recommended that different learning activities should be included in the hospitality, leisure, and tourism programmes to meet the needs of the international student body. These activities include for example consideration of international research, applying theories in an international context and using international material in case studies and other assignments. In addition, it is important to use small group discussions with international aspects and to require demonstration of international knowledge from students. Foreign language studies should be encouraged and students should develop cultural sensitivity and understanding of diversity preferably by meeting international students and drawing on their experience in class. According to Black (2004), using workshops, seminars, group projects and any of a range of activities in which students work together in small groups, enables students to learn from each other.

Furthermore, Sangpikul (2009) identified four possible levels in the internationalisation of the curriculum in hospitality and tourism programmes. Each level has different degrees of curriculum internationalisation beginning from infusing international dimensions into the course contents to establishing joint degree programmes with foreign universities. In other words, the first level consists of infusion of international dimensions into the existing courses by giving additional lectures, case studies, readings and assignments involving international contexts. At the second level international courses are added to a curriculum which is shared by more than one country. At the third level an international degree is offered where the ingredients of the programme (e.g. faculty, courses, teaching methods) reflect and focus on international contexts. At the fourth level joint programmes with foreign universities are developed in collaboration. In this case, a degree can be studied in one university or in joint degree programmes, where the degree is received from two universities. 
Brookes and Becket (2011) created a framework for evaluating the internationalisation of hospitality programmes. The key indicators of the internationalisation of the curriculum included programme aims and learning outcomes, content of teaching that focus on the European and global business environments, and learning activities such as international case studies and learning material.

In the following sections, the main aspects in the internationalisation of the curriculum from the perspective of curriculum design are examined on the basis of the practical process of developing a curriculum of tourism business development in the Central Baltic Area.

\section{Curriculum Design in Practice: The Case of the Central Baltic Area}

The development of a new curriculum was started in November 2016. A joint curriculum was designed to support the development of the Central Baltic Area as a common tourism destination. The first phase was to identify the skills and knowledge needed in the area to be included in the curriculum. In practice, a research was conducted in Finland, Estonia and Latvia with data collected from each country on the necessary skills and knowledge by using different sources. In the second phase, the identified skills and knowledge were translated into the new curriculum of tourism business development and teaching processes.

\section{Identifying the Industry Needs and Expectations}

An international team of tourism lecturers, consisting of 12 persons from four universities (Satakunta University of Applied Sciences, Finland; Tallinn University of Technology, Estonian Maritime Academy, Estonia; Vidzeme University of Applied Sciences, Latvia; University of Latvia, Latvia), identified the relevant skills and knowledge of tourism business development for curriculum design by performing research activities. Three research teams 
were formed, one in each country, to collect and analyse the data. One of the universities led the research activities and provided the research design.

The data for the research were collected in two rounds by prioritizing the needs and expectations of the tourism industry. The research was started by selecting secondary data: national tourism development strategies and plans $(\mathrm{N}=3)$ and the curricula of 17 existing tourism and hospitality bachelor degree programmes in Finland $(\mathrm{N}=7)$, Estonia $(\mathrm{N}=3)$, and Latvia $(\mathrm{N}=7)$. It was considered important to understand strategical level requirements about the needed skills and knowledge in the countries and well as the content of the existing curricula.

The team of lecturers collected primary data by semi-structured individual and group interviews. Altogether 103 industry professionals were interviewed face-to-face or by Skype in Finland $(\mathrm{N}=32)$, Estonia $(\mathrm{N}=27)$, and Latvia $(\mathrm{N}=44)$ to receive the insights of the industry. The informants represented various tourism sectors and actors affected by the decisions on curricula: micro, small, and medium-size tourism enterprises, national and regional tourism development organisations (national tourism boards, regional councils, destination marketing organisations, tourism clusters and tourism-related projects), local tourism information centres and municipal agencies responsible for tourism development, tourism-related associations and tourist attractions. The selected informants worked in different tourism destinations in each country and they were considered the key actors of the tourism industry in their destinations.

The set of questions included the following themes: 1) personal information of the informant (position and/or ownership, professional experience and educational background), 2) future business challenges and obstacles in tourism business development, and 3) skills and knowledge to support the growth and competitiveness of the industry and the organisation (the most meaningful factors in choosing an employee, skills and knowledge needed in fostering the development of the industry and the organisation). The questions were adapted to each situation 
with extra questions and new themes if needed. The interviews were performed until the received information reached a saturation point, which is one of the standard criteria for qualitative data gathering.

The strategies, existing curricula and interviews were analysed with qualitative content analysis to identify themes and patterns. According to Krippendorf (2013), content analysis is a research technique for making replicable and valid inferences from texts to the contexts of their use. In this study, the qualitative content analysis was about systematically transforming a large amount of texts into an organised and concise summary of key results.

The analysis was inductive following the coding technique of Miles and Huberman (1994) and new categories were formulated out of the data. First, the data were collected by interviews and the interviews were transcribed. Then the strategies and curricula were selected for analysis. All the texts were studied carefully several times to acquire a sense of the whole and to identify the essential features of the content for further analysis. The texts were divided into meaning units and codes were generated with an inductive coding system from the sentences related to skills and knowledge needed in tourism business development. In the following stage categories i.e. groups of content which share a commonality (Krippendorff, 2013) were generated by grouping codes. The observations were inserted on a qualitative data category card. A constant comparative method was used and each text was compared with those already assigned to that category. The aim of grouping the data was to reduce the number of categories by incorporating those which are similar or dissimilar into broader higher order categories.

The credibility of the findings was explored by member checking. The findings were also shared with the tourism industry professionals in several occasions, where they were able to critically analyse and comment on them. Various seminars and workshops were organised for example in the Nordic Travel Fair 2018, International Travel Trade Fair Balttour 2018 and the 
Baltic Sea Tourism Forum to present and elaborate on the findings. In addition, the international team of lecturers cross-checked the findings in each country and compared the results of each country to reach a consensus on the mutual skills and knowledge needed.

\section{The Necessary Skills and Knowledge in Tourism Business Development}

The analysis resulted in the identification of five categories of skills and knowledge relevant for the growth and competitiveness of the Central Baltic Area as a coherent tourism destination: 1) product and experience design and development, 2) multi-channelled sales and marketing communication, 3) multi-sectorality, cooperation and networking, 4) cultural awareness and internationalisation, and 5) managing business operations and entrepreneurial competence.

The main challenges in product and experience design and development are associated with creating unique, authentic and innovative tourism products and experiences without losing connection to local values. A broader view is necessary in order to identify the business opportunities in a multi-sectoral business environment and to develop competitive and versatile offerings from the interfaces of tourism and other fields (for example culture, nature, and food). In addition, it is necessary to develop high-quality products for specific segments, which exceed the customers' expectations, as well as to tailor and adjust products. Sustainability, including its economic aspects, was regarded as a key value in product and experience development. As seasonality is one of the major challenges in the tourism industry, the role of product development for off-season and low season periods should be highlighted in the curriculum content. Informant from a tourism cluster expressed this in the following way:

"We need more experience-based products in well-being tourism. For this reason, we should know the effects of the sea on well-being better to be able to productise these experiences in our coastline." 
The skills in multi-channelled sales and marketing communication such as the use of digital channels are a priority - the trends of the digitalisation and future technologies define the tourism business and make it global. Digitalisation, from understanding the concepts to the usage of the specific tools, was considered the biggest challenge in the industry. Therefore, a variety of information and communication technology (ICT) skills, from the use of social media and productisation of high quality virtual materials to creative design, should be strengthened among tourism students and tourism professionals of all age groups. Different aspects of online visibility are very important, for example well designed, interactive websites, active social media accounts and useful mobile applications.

The bottlenecks in the tourism industry are created by lack of sales skills and knowledge of different sales channels. Sales skills refer to the proactive, goal oriented approach of the staff to increasing offline and online sales. It includes predicting and understanding the buying behaviour in tourism and offering and presenting products in a sophisticated manner. In addition, it is necessary to establish optimal systems for searching travel products online and for selling products in the context of multiple domestic and international sales channels and models. An informant from a regional council saw that:

"Professionals do not have skills in selling tourism products in digital sales channels. The products are not visible enough and the use of digital sales channels is confusing. The buyer cannot buy the products online. In addition, there is not enough information available in English about our destination."

The role of collaboration is indisputable in the bid to reach more international tourists. It explains the significance of the skills related to multi-sectorality i.e. involving more than one sector of the tourism industry in business activities, collaboration, and networking. The actors in the tourism industry do not have sufficient skills and knowledge of how to collaborate in practise. It is obvious that there is a need to establish new collaboration models and multi- 
sectoral cooperation. It is necessary to strengthen rational understanding of how to utilize strategic partnerships and cluster networks in tourism business development. The key skills include networking and establishing networks to enhance collaborative product development, sales and marketing activities to reach certain segments and markets jointly. A tourism entrepreneur from a micro-sized company commented the role of the entrepreneurs:

"The entrepreneurs work too much on their own. We do not understand that we are able to increase our visibility only by networking. We have to provide our services jointly to become an interesting destination from the tourists' point of view. We have to become more goaloriented and also cooperate with the municipalities and regional authorities. “

The skills in the category of cultural awareness and internationalisation include an ability to identify and reach diverse international target groups. It is necessary to understand the special characteristics of people from different cultures and their sensitivity to product offerings. Therefore, actors in the field of tourism need knowledge of the markets, especially of the Asian tourism markets. The increasing diversity of international tourists and their demands on international customer service also pose new skill requirements. As a result, the specific characteristics of different cultures and their influence on customer service should be highlighted. In addition, persons working in the tourism industry need knowledge of their own culture. An informant from a destination marketing organisation criticized that:

" The target groups are changing and the number of Asian tourists is increasing. We need more skills in international customer service. Both entrepreneurs and employees should understand their international customers better."

Skills related to the management of business operations involve knowledge of operational and strategic management issues as well as skills in developing business operations in the SMEs. Many representatives of the tourism industry claim that there is a need for entrepreneurial competence. Entrepreneurial competence refers to the skills in running a 
profitable business and in increasing the competitiveness of an enterprise in a specific operational environment. Especially younger staff members need skills in team and human resource management. The staff should also have skills in risk management and financial skills including the basic principles of product pricing. In addition, it is necessary to intensify the overall usage of digital technologies in business operations. Significant strategic competence includes an ability to identify and interpret the changes in tourism business environments in the global and local context. In addition, it involves developing analytical foresight skills and awareness of trends as well as understanding tourism as a system.

Personal traits and language skills emerged as cross-cutting themes. The employees have to show a welcoming attitude, hospitality, openness, sense of empathy, civility, accuracy and diplomacy. Additionally, development of personal characteristics is significant for building careers in tourism. Therefore, innovativeness, creativeness and proactivity should be emphasised.

The informants referred to language skills as a highly important competence. Serving the tourists in their own language was regarded as excellent customer service and thereby the customer's expectations can be exceeded. In Finland, persons working in the field of tourism should also know other European languages than English, since the number of international tourists is increasing and the travel market is diversifying. The Latvian informants expressed lack of language skills in Russian as the biggest problem. It has disappeared from the toolbox of the young employees but it is extremely important as the market for Russian speaking people is wide and geographically in the neighbourhood. In all three countries, German is needed in addition to English.

Translating the Needs and Expectations of the Industry into Courses and a Curriculum 
After the completion of the analysis, the needs and expectations of the industry were translated into course contents. The international team of lecturers reviewed the categories of skills and knowledge for designing the curriculum. In a workshop in May 2017, the lecturers chose the topics of the courses and shared them for further course design; eight courses in total, two courses per university. The next stage involved working jointly in an online environment to develop the preliminary course descriptions including the purpose of each course, the keywords describing the course content as well as the most important learning outcomes. One of the universities defined the purpose and the learning outcomes for the whole curriculum on the basis of the data. In addition, the lecturers elaborated the course descriptions jointly to avoid overlapping contents and gaps between the courses in a workshop in November 2017. In this workshop, the course descriptions were discussed in detail to ensure their coherence.

Next, the lecturers concentrated on internationalising the teaching process and developed their courses further. Each lecturer wrote a course syllabus with the following essential information: purpose, content, learning outcomes, learning activities, assessment, and resources. For finalising the syllabi, the international team of lecturers had a meeting in March 2018. The discussions mainly concentrated on assessment and the different learning activities included in the curriculum to meet the needs of an international student body. Also, an eLearning expert provided information and support in the principles and details of course design in eLearning.

\section{Purpose, Key Learning Outcomes and Course Contents}

In the following stage, the needs and expectations of the industry were translated into the purpose, key learning outcomes and contents of eight courses. The courses were created around the most relevant topics that should be covered in the curriculum according to the research findings. The curriculum design was guided by the rationale and purpose of the curriculum, i.e. 
the development of the Central Baltic Area as a coherent and international tourism destination. Because the curriculum is integrated as a module in the existing tourism degree programmes of the universities, the skills and knowledge already covered in those curricula (e.g. entrepreneurial skills, language skills) were discussed and left out.

The name of the new curriculum is "Boosting the Growth of Tourism Business Supporting the Development of the Central Baltic Area as a Coherent Tourism Destination" because of its rationale and purpose. The purpose of the curriculum is to provide an aligned and mutual skillset and knowledge necessary for meeting the challenges and for using the possibilities of the tourism industry because tourism is expected to increase its importance and continue growing. When taking these studies, the students acquire specialised tourism business development skills and knowledge relevant to various tourism-related sectors and actors for boosting the growth and competitiveness of the industry. The curriculum enables students to develop skills and knowledge needed in coping with the changing circumstances of tourism business, especially with the growth of international tourism in the area. The curriculum is targeted at the second, third, and fourth year tourism and hospitality bachelor degree students. In addition, the courses are offered for professionals as in-service training.

The core courses aim at increasing the key skills and knowledge in designing experiencebased products to deal with the challenges related to seasonality, managing marketing communication in tourism organisations and developing successful, multi-sectoral cooperation in destinations. In addition, the students acquire skills and knowledge in international customer service and develop sensitivity to cultural differences. They gain skills and knowledge in selling destinations, tourism products and services to meet specific customer needs. The students are introduced to different methods and tools to forecast global changes and their impact on tourism businesses. The studies also aim at developing the students` personal traits. 
The extent of the curriculum is 33 ECTS credits. The curriculum is placed at level 6 in the European Qualifications Framework (EQF) and taught $100 \%$ in English. In total, the curriculum includes the following courses:

- Tourism Product and Experience Design, 6 ECTS

○ Digital Marketing Communication and Content Management, 6 ECTS

○ Increasing Competitiveness by Cooperation, 6 ECTS

- Boosting Sales in Tourism, 3 ECTS

○ Cultural Competence in Customer Service, 3 ECTS

- Forecasting Tourism in the Age of Uncertainty, 3 ECTS

- Proactivity and Creative Performance, 3 ECTS

○ Innovation Camp in Product Development, 3 ECTS

Students get six ECTS credits from three core courses and three ECTS credits from five specialisation courses. The core courses enhance skills and knowledge in product and experience design, digital marketing communication and content management and cooperation and networking. Five specialisation courses improve skills and knowledge in boosting sales in tourism, international customer service, forecasting the impacts of global change on tourism businesses and proactivity and creativeness.

A variety of international study materials are incorporated into course content to gain international understanding of the tourism industry. Besides the textbooks, articles and reports, the study material includes examples and practices from different countries and target markets with the focus on the Central Baltic Area, which are investigated and compared in the courses.

The studies are mainly implemented online, which increases the flexibility of studying. However, one course is carried out as an innovation camp in Estonia, where the students meet and exchange ideas. The purpose of the innovation camp is to deepen the expected learning outcomes of the curriculum in active exchange of ideas and constructive feedback in a 
multicultural setting. The focus of the camp is on the innovative and creative design of tourism products for low season periods. The camp includes a learning café, where national examples from three countries are exchanged, compared and analysed jointly. The camp also includes practical seminars, hands-on workshops, testing local tourism products and a field trip to meet local tourism entrepreneurs.

The curriculum delivery is created around meaningful, real-life cases in order to support the development of the industry and to integrate learning and tourism industry better. As a result, there is more interaction between the tourism industry and higher education institutions. For example, students develop multi-channelled sales concepts and digital content strategies in groups. They prepare scenario analysis and low-season rural tourism tours for different target markets. It is necessary to analyse the available data to resolve the cases and develop proposals for action. Students are encouraged to learn by collecting material from tourism organisations in field trips and by observing and interviewing the industry representatives. Finally, the solutions are presented to the representatives of the industry.

Group work has a major role in the curriculum. In addition to the individual assignments, the students study in multicultural groups online when resolving these industry cases. Group assignments require intercultural communication and integration of cultural aspects: each group consists of students from Finland, Estonia, and Latvia. International exchange students are also encouraged to participate. Studying in these multicultural groups enhances the student's intercultural competence.

Several assessment techniques are used to assess all students effectively. All courses are evaluated by a lecturer and a group of students or alternatively by the peers. Self-assessment and reflection are included in course assignments. Feedback from the industry is also requested.

\section{Resources}


The use of ICT presents possibilities for the internationalisation of the curriculum in higher education and supports novel forms of distance education (Callan, 2000; Svensson \& Wihlborg, 2010). In this case, all the courses of the curriculum, except the innovation camp, are provided completely online. Therefore, the lecturers should have similar, aligned ICT skills to guarantee the coherence of the courses provided in the virtual learning environment. However, the lecturers have different skills and knowledge of the pedagogy of eLearning. Therefore, it is also necessary to have an ICT expert in the team supporting the curriculum design and delivery.

A prerequisite for successful learning is a reliable, well-functioning technical application. In this case, a special concept is used to guide learning and interaction between students irrespective of place. Satakunta University of Applied Sciences has developed in partnership with ICT companies a unique, online learning environment, HILL, which enables the lecturer to teach online in the same way as in the classroom. The courses are delivered online though this learning environment and they include real-time online lectures, which are recorded and can be viewed later. Teachers are also available online for consultations at certain hours. In addition, an online learning environment Moodle is used in the course delivery. Students can interact through the HILL learning environment or Skype when working in the groups.

\section{Discussion and Conclusion}

Because of the structural changes in higher education, higher education institutions are under pressure to renew their curriculum and their pedagogical approaches in the Central Baltic Area. This case has provided them various benefits. The universities participating in the curriculum design process have stressed that curriculum and course development have broadened their areas of expertise. The process has increased, in particular, understanding of the skills and knowledge needed to enable them to provide more industry-oriented education. By receiving feedback from the industry, the lecturers become more aware of and are able to examine their 
pedagogical choices critically. In addition, the universities participating have reported that provision of jointly designed and delivered courses enhances the digitalisation of the universities and encourages them to further develop digital pedagogy. The pedagogical material will benefit the education system as such, because new curriculum contents, pedagogical practices and experiences will be introduced. The curriculum will also save resources in the future, because the students are able to participate in several courses provided jointly by the four universities.

The article emphasises the role of lecturers, since they represent a group of employees most deeply affected by internationalisation. They are in charge of integrating the international perspectives into the curriculum in a planned and systematic way (Ayoun et al., 2010; Leask, 2011). These decisions also include shared interpretations of curriculum design and delivery (Korhonen \& Weil, 2015). In this case, the lecturers were at the heart of the process of the internationalisation of the curriculum design. It is of utmost importance that they have similar skills and shared interpretations of intercultural teaching and eLearning. They should acknowledge the specific requirements in teaching and learning in an international online learning environment. Thus, skills in teaching online and an advanced online learning environment were the first prerequisites for designing and delivering a joint curriculum in cooperation by four universities in three countries.

In addition, destination competitiveness is only possible in the area if skills and knowledge are improved. The national tourism strategies and plans (Ministry of Economics of the Republic of Latvia, 2017; Visit Estonia, 2017; Visit Finland, 2017) emphasise the fact that a better balance should be achieved between skilled labour supply and demand. One of the main challenges in these countries is to improve education and skills in order to respond to the growth of tourism. The jointly designed curriculum provides a great tool for addressing the common issues in tourism development in these countries. 
The common challenges and possibilities as well as the similar target markets in tourism business development in Finland, Estonia and Latvia supported the internationalisation of the curriculum design. It facilitated reaching a consensus about the mutual skills and knowledge needed in the curriculum content. However, there were minor differences between the countries. For example in Finland, digitalisation, product development, sales and cooperation were considered essential skills, whereas in Latvia development of personal traits was emphasised. It was more challenging to reach common understanding about the rationale and the purpose of the curriculum design, especially in the beginning of the process. Due to the differences in tourism systems in the participating countries, the selection of tourism professionals for the interviews required a thorough discussion.

Furthermore, this case shows that themed degrees are needed alongside with the generic degrees. The categories of skills and knowledge relevant for the growth and competitiveness of the Central Baltic Area as a coherent tourism destination emphasise the specialist knowledge and expertise. As Dale and Robinson (2001) argued, programme developers need to seek out new ways for ensuring that graduates have an ability to add value to tourism organisations. For this purpose, they suggested theming tourism education, i.e. to differentiate the offering from competitors and provide graduates themed degree routes, which equip them with specialist skills. Dale and Robinson (2001) referred to market/product-based degrees which would enable the graduates to meet the needs of the stakeholders. These degrees focus on the nature and development of particular niche products and markets, which require specialist knowledge and expertise. This kind of skills and knowledge are also required in the Central Baltic Area, which makes a themed degree highly relevant.

Tourism curricula cannot be designed in isolation. It is recommended that higher education institutions consider the rationales and purpose when internationalising their curriculum. If tourism is to contribute to economic regeneration and to the growth and 
competitiveness of destinations and businesses, it is necessary to understand the needs and state of the art of the tourism industry. First, the rationales and the purpose of the curriculum should be established with regard to the challenges and requirements of the industry. Second, the courses should be planned based on this understanding. In this process, it is important to take the opinions of various groups of stakeholders working in the tourism industry into consideration. The curriculum cannot be internationalised without a firm understanding of why it needs to be internationalised.

However, limitations of this curriculum design process are related to its strong regional focus. The rationale and the purpose of the curriculum derived from the regional strategies, which affected the content of the curriculum and courses. In addition, the curriculum was defined as a series of courses packed into a specialisation module of tourism business development (33 ECTS credits), not as a curriculum of a degree programme. The needed skills and knowledge are vocational i.e. the curriculum provides practical skills to bring profit to the organising enterprise and satisfaction to the paying tourist. In case of a whole degree programme, more multi-disciplinary approach is needed. It is hoped that the future studies will apply the curriculum design process also in the context of tourism degree programmes.

Higher education institutions can use the information of skills and knowledge requirements in the tourism industry and the example of curriculum design process when planning their educational activities. The article provides a valuable example for higher education institutions of how to internationalise the curriculum in practise. The tourism organisations can use the information as a guideline to ensure that their employees have the relevant skillset and in recruiting new employees.

\section{Funding details}


This work was supported by the European Territorial Cooperation (Interreg) Central Baltic Programme 2014-2020

\section{References}

Altbach, P., \& Knight, J. (2007). The internationalization of higher education: Motivations and realities. Journal of Studies in International Education, 11(3-4), 290-305.

Ayoun, B., Johnson, M., Vanhyfte, M., \& O'Neill, M. (2010). A comparison study of US and non-US education internationalization practices of hospitality and tourism programs. Journal of Teaching in Travel \& Tourism, 10(4), 335-361.

Black, K. (2004). A review of factors which contribute to the internationalisation of a programme of study. Journal of Hospitality, Leisure, Sport and Tourism Education, 3(1), $5-18$.

Brookes, M., \& Becket, N. (2011). Internationalising hospitality management degree programmes. International Journal of Contemporary Hospitality Management, 23(2), $241-260$.

Callan, H. (2000). Higher education internationalization strategies: Of marginal significance or all-pervasive? The international vision in practice: A decade of evolution. Higher Education in Europe, 25(1), 15-23.

Central Baltic Programme 2014-2020. Programme Document. Retrieved from http://centralbaltic.eu/sites/default/files/documents/Central\%20Baltic\%20Programme\% 20Document_0.pdf

Dale, C., \& Robinson, N. (2001). The theming of tourism education: a three-domain approach. International Journal of Contemporary Hospitality Management, 13(1), 3035 .

Deale, C. (2015). Hospitality and Tourism Education in the International Classroom: A Case Study. Journal of Teaching in Travel \& Tourism, 15(4), 301-324.

deWit, H. (2010). Internationalisation of Higher Education in Europe and its assessment, trends and issues. The Accreditation Organisation of the Netherlands and Flanders.

deWit, H. \& Hunter, F. (2015). Understanding internationalisation of higher education in the European context. In European Parliament (Ed.), Internationalisation of Higher Education (pp. 41-58). Study. Policy department B: Structural and cohesion policies.

deWit, H., Deca, L., \& Hunter, F. (2015). Internationalization of higher education-What can research add to the policy debate? In A. Curaj, L. Matei, R. Procopie, J. Salmi \& P. Scott 
(Eds.), The European Higher Education Area. Between Critical Reflections and Future Policies (pp. 3-12). London: Springer International Publishing.

Dobbins, M., Knill, C., \& Vögtle, E. (2011). An analytical framework for the cross-country comparison of higher education governance. Higher Education, 62(5), 665-683.

Dunne, C. (2011). Developing an intercultural curriculum within the context of the internationalisation of higher education: Terminology, typologies and power. Higher Education Research \& Development, 30(5), 609-622.

Garam, I. (2016). International mobility in Finnish higher education in 2015: degree students. Retrieved from http://www.cimo.fi/instancedata/prime_product_julkaisu/cimo/embeds/cimowwwstruct ure/111327_Facts_and_figures_5b_2016.pdf

Gunn, C. (1998). Issues in tourism curricula. Journal of Travel Research, 36(4), 74-77.

Hearns, N., Devine, F., \& Baum, T. (2007). The implications of contemporary cultural diversity for the hospitality curriculum. Education+ Training, 49(5), 350-363.

Jordan, F. (2008). Internationalisation in hospitality, leisure, sport and tourism higher education: A call for further reflexivity in curriculum development. Journal of Hospitality, Leisure, Sports and Tourism Education, 7(1), 99-103.

Knight, J. (2004). Internationalization remodeled: Definition, approaches, and rationales. Journal of studies in international education, 8(1), 5-31.

Knight, J. \& de Wit, H. (1995). Strategies for internationalisation of higher education: historical and conceptual perspectives. In H. De Wit (Ed.), Strategies for the Internationalisation of Higher Education. A Comparative Study of Australia, Canada, Europe and the United States of America (pp. 5-32). Amsterdam: European Association for International Education.

Korhonen, V., \& Weil, M. (2015). The internationalisation of higher education: Perspectives on self-conceptions in teaching. Journal of Research in International Education, 14(3), $198-212$.

Krippendorf, K. (2013). Content Analysis. An Introduction to Its Methodology. Thousand Oaks: Sage.

Laitinen, M. (2015). Finland. In European Parliament (Ed.), Internationalisation of Higher Education (pp. 85-96). Study. Policy department B: Structural and cohesion policies.

Leask, B. (2005). Internationalisation of the curriculum: teaching and learning. In J. Carroll \& J. Ryan (Eds.), Teaching International Students. Improving Learning for All (pp. 119129). London: Routledge. 
Leask, B. (2009). Using formal and informal curricula to improve interactions between home and international students. Journal of Studies in International Education, 13(2), $205-221$.

Leask, B. (2011). Assessment, learning, teaching and internationalisation - engaging for the future. Assessment, Teaching \& Learning Journal, 11, 5-20.

Leask. B. (2015). Internationalizing the Curriculum. London: Routledge.

Luxon, T., \& Peelo, M. (2009). Internationalisation: Its implications for curriculum design and course development in UK higher education. Innovations in Education and Teaching International, 46(1), 51-60.

Miles, M., \& Huberman, A. (1994). Qualitative Data Analysis: An Expanded Sourcebook. Thousand Oaks: SAGE Publications.

Ministry of Economics of the Republic of Latvia. (2017). Regional Survey of Tourism Development of Latvia. Retrieved from https://www.interregeurope.eu/fileadmin/user_upload/tx_tevprojects/library/file_15082 54284.pdf

Reid, S. \& Spencer-Oatey, H. (2013). Towards the global citizen. Utilising a competency framework to promote intercultural knowledge and skills in higher education students. In J. Ryan (Ed.), Cross-Cultural Teaching and Learning for Home and International Students (pp. 125-140). New York: Routledge.

Ryan, J. (2005). Improving teaching and learning practices for international students. Implications for curriculum, pedagogy and assessment. In J. Carroll \& J. Ryan (Eds.), Teaching International Students. Improving Learning for All (pp. 92-100). London: Routledge.

Sangpikul, A. (2009). Internationalization of hospitality and tourism higher education: a perspective from Thailand. Journal of Teaching in Travel \& Tourism, 9(1-2), 2-20.

Svensson, L., \& Wihlborg, M. (2010). Internationalising the content of higher education: the need for a curriculum perspective. Higher Education, 60(6), 595-613.

Takagi, H. (2015). The internationalisation of curricula: the complexity and diversity of meaning in and beyond Japanese universities. Innovations in Education and Teaching International, 52(4), 349-359.

Teichler, U. (2004). The changing debate on internationalisation of higher education. Higher Education, 48(1), 5-26.

Tribe, J. (2002). The philosophic practitioner. Annals of Tourism Research, 29(2), 338-357. 
Visit Estonia. (2017). Tourism in Estonia in 2016. Retrieved from https://static1.visitestonia.com/docs/3024432_tourism-in-estonia-2016.pdf

Visit Finland. (2017). Tourism in Finland - Key facts and figures. Retrieved from http://www.visitfinland.fi/en/tourism-in-finland/

Webb, G. (2005). Internationalisation of curriculum: an institutional approach. In J. Carroll \& J. Ryan (Eds.), Teaching International Students. Improving Learning for All (pp. 109118). London: Routledge.

Werner, E. (2008). The Bologna Process: Building Bridges for Education Internationalization and the Bologna Process: What does it mean for European Higher Education Institutions? Journal of Hospitality \& Tourism Education, 20(1), 6-12.

Williams, K., \& Best, G. (2014). Short study tours abroad: Internationalizing business curricula. Journal of Teaching in Travel \& Tourism, 14(3), 240-259.

Zehrer, A., \& Lichtmannegger, S. (2008). The internationalization of tourism education-the case of MCI. Journal of Hospitality \& Tourism Education, 20(1), 45-51.

Zhang, L., Lu, T., Hu, H., \& Adler, H. (2009). An exploratory study of the internationalization of tourism higher education in China. Journal of Human Resources in Hospitality \& Tourism, 9(1), 33-46. 
Table 1. The main areas of the internationalisation of the curriculum design modified on the basis of Brookes and Becket (2011), deWit (2010) and Leask (2005).

\begin{tabular}{|l|l|}
\hline $\begin{array}{l}\text { Key areas of } \\
\text { importance }\end{array}$ & Questions \\
\hline Rationales & Why is the curriculum internationalised? \\
\hline Purpose & What is accomplished by internationalising the curriculum? \\
\hline Outcomes & $\begin{array}{l}\text { What international perspectives should graduates in this } \\
\text { professional area develop? }\end{array}$ \\
\hline Content & $\begin{array}{l}\text { What international content will students need in order to } \\
\text { develop these perspectives? }\end{array}$ \\
\hline Learning environment & $\begin{array}{l}\text { What learning activities and tasks will assist learners to develop } \\
\text { these perspectives and prepare them for assessment? }\end{array}$ \\
\hline Assessment & $\begin{array}{l}\text { What kind of assessment task(s) could students complete to } \\
\text { demonstrate the achievement of these perspectives? }\end{array}$ \\
\hline Resources & $\begin{array}{l}\text { What resources (people, online tools) are available for the } \\
\text { achievement of the above mentioned goals? }\end{array}$ \\
\hline
\end{tabular}

